WellBeing International

WBI Studies Repository

2010

\title{
Male Territoriality in a Social Sciurid, Cynomys gunnisoni: What do Patterns of Paternity Tell Us?
}

\author{
J. L. Verdolin \\ Stony Brook University \\ C. N. Slobodchikoff \\ Northern Arizona University
}

Follow this and additional works at: https://www.wellbeingintlstudiesrepository.org/acwp_vsm

Part of the Animal Studies Commons, Behavior and Ethology Commons, and the Comparative Psychology Commons

\section{Recommended Citation}

Verdolin, J. L., \& Slobodchikoff, C. N. (2010). Male territoriality in a social sciurid, Cynomys gunnisoni: what do patterns of paternity tell us?. Behaviour, 147(9), 1145-1167.

This material is brought to you for free and open access by WellBeing International. It has been accepted for inclusion by an authorized administrator of the WBI Studies Repository. For more information, please contact wbisr-info@wellbeingintl.org.

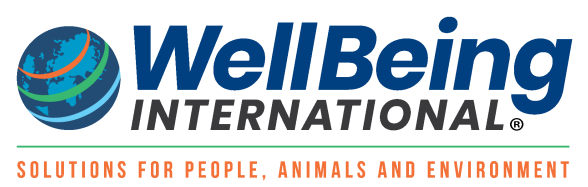




\title{
Male Territoriality in a Social Sciurid, Cynomys gunnisoni: What do Patterns of Paternity Tell Us?
}

\author{
J.L. Verdolin ${ }^{1}$ and C.N. Slobodchikoff ${ }^{2}$ \\ ${ }^{1}$ Stony Brook University \\ ${ }^{2}$ Northern Arizona University
}

\section{KEYWORDS}

reproductive success, mating system, mating strategy, sociality, territoriality, Cynomys

\begin{abstract}
In many social sciurids, male territoriality confers significant mating advantages. We evaluated resident male paternity in Gunnison's prairie dogs (Cynomys gunnisoni), a colonial ground-dwelling sciurid, where males and females cooperatively defend territories. Contrary to findings reported for other social sciurids, our results show that territorial resident males do not gain significant reproductive advantages. Resident males sired the majority of offspring from their respective territories only $10.5 \%$ of the time. A single nonresident male sired equal or greater number of offspring than any single resident male $71.2 \%$ of the time. While adult males were more likely to sire a greater number of offspring, standard heterozygosity, body mass, and territory size were not significant predictors of how many offspring a male sired. In addition, the number of other males present did not influence the number of offspring sired by any given resident male. However, territory size was significantly correlated with overall offspring number and mean litter size per female, suggesting a potential reproductive advantage for females that occupy larger, better quality territories. Previous work has demonstrated that the cooperative defence of territories by both males and females permits enhanced access to food resources critical to overwinter survival. Our results have important implications for studies that do not distinguish between social and mating systems, because they suggest that individual mating strategies may be different from the social strategies that emerge in response to resource availability.
\end{abstract}

\section{Introduction}

Typically, variations in male mating strategies are evaluated against the background of the polygynythreshold model (Verner, 1964; Verner \& Willson, 1966; Orians, 1969;Wittenberger, 1976) and the environmental potential for polygyny model (Emlen \& Oring, 1977). In general, these models predict that males control access to females directly (female defence polygyny) or indirectly through resources (resource defence polygyny). However, extensive studies of mating success have demonstrated that the social mating system and the genetic mating system of a species can be quite distinct (Birkhead et al., 1987; Davies, 1991; Lott, 1991; Kitchen et al., 2006; Kyle et al., 2007), suggesting that broadly 
categorizing populations solely on the basis of observable patterns of social association between males and females may not reflect the true genetic mating system. By evaluating social and mating systems in the context of individual fitness enhancing strategies (Vehrencamp \& Bradbury, 1984; Davies, 1991), the factors that influence reproductive success become critical to understanding the variance observed among individuals.

In species where the social and mating systems are dissimilar, the social context can exert a strong influence on male reproductive success. For example, under the female defence polygyny model, territorial males may monopolize access to females through male-male competition, herding of females, or mate-guarding (Bradbury \& Vehrencamp, 1977; Emlen \& Oring, 1977; Hanken \& Sherman, 1981). Sometimes males may form coalitions when single males are unable to defend a group of females and the benefits of cooperatively defending females overrides the cost of sharing access to potential mates (Clutton-Brock, 1989; Davies, 1991). However, as additional males are added to a group, the ability of a single male to monopolize mating access may be compromised (Reeve et al., 1998), leading to multiple paternity in social groups that contain multiple males (Goossens et al., 1998; Cohas et al., 2006).

Other factors are also expected to influence patterns of reproductive success among males, including age, body size and/or mass, territory size, genetic relatedness to females, and genetic heterozygosity (Shine et al., 2000; Amos et al., 2001; Brooks \& Kemp, 2001; Höglund et al., 2002; Mainguy et al., 2009; Moore et al., 2009). Male age is one of the most reliable predictors of inter-male variation in mating success, particularly in birds (reviewed in Griffith et al., 2002). Older males may have a higher reproductive output because such males have demonstrated an ability to survive, are more successful foragers, or generally are more experienced than younger males, thereby enhancing their attractiveness to females (Trivers, 1972; Manning, 1985; reviewed in Brooks \& Kemp, 2001).

For many species there is empirical support for the importance of male body size and/or mass in determining reproductive success, either as a result of enhanced fighting ability or defence of superior territories (Andersson, 1994). Larger males may be able to retain exclusive access to females, successfully guard a larger number of females, or defend territories that overlap more females than smaller males (Clutton-Brock, 1989; Moore et al., 1990; McElligott et al., 2001). Females, in turn, may prefer larger, heavier males because such traits may be indicative of foraging success and overall genetic fitness, resulting in improved offspring survival and fitness (Kodric-Brown \& Brown, 1984).

Lastly, the underlying genetic background of males can have a significant effect on individual reproductive success. Inbreeding avoidance is well established and may explain patterns of multiple paternity under the 'compatible genes' hypothesis (Jennions \& Petrie, 2000; Mays \& Hill, 2004; Neff \& Pitcher, 2005; Thuman \& Griffith, 2005; Vanpé et al., 2009; but see Lane at al., 2007). More recently, the potential influence of genetic heterozygosity on the variance of reproductive success among males has been examined (Brown, 1997; Jennions \& Petrie, 2000). Evidence from natural populations suggests that high levels of homozygosity can reduce survival (Soay sheep: Coltman et al., 1999; Song sparrows: Keller, 1998; Collared flycatcher: Kruuk et al., 2002). Because increased offspring heterozygosity may improve offspring fitness (Brown, 1997; Foerster et al., 2003), males with higher levels of heterozygosity are expected to have greater reproductive success.

Within the ground squirrels, multiple mating by females is common in several species (Hanken \& Sherman, 1981; Sherman, 1989; Schwagmeyer \& Foltz, 1990; Boellstorff et al., 1994; Murie, 1995; Michener \& McLean, 1996; Lacey et al., 1997), including the highly social, territorial Gunnison's prairie dog (Cynomys gunnisoni) (Travis et al., 1995, 1996; Hoogland, 1998; Haynie et al., 2003). Both males and females occupy territories composed of variable social groups, ranging from single male-single female associations to larger multimale-multifemale groups (Slobodchikoff, 1984; Travis \& Slobodchikoff, 
1993; Travis et al., 1995; Verdolin, 2007, 2009; Verdolin \& Slobodchikoff, 2009). Territories persist in space and time, with both males and females defending territory boundaries from intruders (Rayor, 1988; Verdolin, 2007). However, females range further than males during the brief mating season and are frequently observed in the company of males from other territories (Verdolin, 2007). Previous studies report that $60 \%$ of pups born to any given female are not sired by the resident male/s on her territory (Travis et al., 1995, 1996). Thus, not only is the frequency of multiple paternity high in this species, but a large portion of offspring are sired by males from other territories.

Past studies have characterized Gunnison's prairie dog males as pursuing a harem-defence (femaledefence) mating strategy (Fitzgerald \& Lechleitner, 1974; Rayor, 1988; Hoogland, 1999). However, observational and experimental data have failed to support predictions that emerge from either the female defence or resource defence mating system model. For example, Verdolin (2007) found communal defence of territories by both males and females, more extensive ranging by females during the mating season, and a lack of sexual dimorphism. Although previous work established a high occurrence of multiple paternity in this species (Travis et al., 1995, 1996), it remains unclear if resident males sire significantly more offspring in their respective territories than any single non-resident male (males from other territories), thus gaining a significant reproductive advantages despite high multiple paternity. In addition, the factors influencing individual male reproductive success have not been examined.

The purpose of this study was twofold. First, we determine if male mating success conforms to the female defence or resource defence models of male mating strategies. We predicted that if males are pursuing a resource defence or harem defence mating strategy, then resident males are expected to gain direct reproductive benefits, with territory holders siring more offspring in their territory than any other single non-resident male. Alternatively, if males are pursuing a resource-based mating strategy, then males may gain both direct and indirect reproductive benefits, with males occupying the largest territories siring more offspring both inside and outside their territory. If, however, males are not gaining reproductive benefits through territoriality, then resident males and males occupying larger territories are not expected to sire a greater proportion of offspring, both within and outside of their territory. Then, we explore what, if any, factors are important in the reproductive success of individual males. We predicted that age, body mass, territory size, and genetic heterozygosity would be significant predictors of male reproductive success.

\section{Material and methods}

Two colonies of Gunnison's prairie dogs were studied within the city limits of Flagstaff, AZ, USA from May 2003 to August 2005. The first study site, Humane Society (HS), was established in May 2003. The second study site, Country Club (CC) was established in August 2003 (see Verdolin, 2007 for details). Experimental manipulations of resource abundance and distribution were conducted from June 1, 2004August 1, 2004 and April 1, 2005-May 6, 2005. Paternity data presented in this study reflects the mating season prior to experimental manipulations, April 2004. Within each site, HS and CC, two 1 ha plots were established, referred to subsequently as $\mathrm{HSI}, \mathrm{HSII}, \mathrm{CCl}$ and $\mathrm{CCll}$. For each plot a $100 \mathrm{~m} \times 100 \mathrm{~m}$ letter/number grid system consisting of $10010 \times 10$ m quadrats were established using surveyor stakes. Because only a small percentage of the total numbers of juveniles were captured during the 2003 and 2005 seasons, genetic analysis was not undertaken and data from these years are not included.

\section{Behaviour and territory observations}

We assigned individuals to social groups and determined group territory boundaries using data on animal locations collected during live-trapping, focal animal behavioural observations, and scan samples as described in Verdolin (2007). Briefly, prairie dogs were live-trapped with Tomahawk live traps (50 $\times 18 \times$ $18 \mathrm{~cm}$ and $48 \times 15 \times 15 \mathrm{~cm}$ ), baited with sunflower seeds. Individuals were marked with unique symbols 
for identification using black Lady Clairol ${ }^{\circledR}$ hair dye. Individuals were observed during the hours of 07001000 and 1500-1800. Focal samples (5 min) were conducted over a total of approx. $400 \mathrm{~h}$ of observation in 2004 and scan samples were performed every 30 min during observation periods. Locations were recorded based on the proximity (to the nearest $0.5 \mathrm{~m}$ ) of an individual to either a surveyor stake or a flagged burrow and matched with corresponding coordinates obtained with a Garmin ${ }^{8}$ Etrex Global Positioning System. The term social group refers to individuals that are mutually tolerant of each other, as indicated by behaviours such as greet-kisses (King, 1955) and co-feeding, while territory refers to the area occupied and defended by all members of a single social group. Animals that were consistently chased out of an area were considered as not belonging to that territory. Individuals that were trapped once and not seen throughout the study were not included as members of any social group. Behavioural sampling effort was similar across study plots (see Verdolin, 2007 for details).

Territory areas were calculated using the fixed kernel density estimator. Territories were defined as the area occupied by all members of a particular social group and were estimated using the fixed kernel density estimator (ArcView 3.2a; ESRI, 2000). When using the fixed kernel approach with a level of smoothing selected by least squares cross-validation (LSCV), results are less biased and more appropriate for non-normal distributions (Worton, 1995; Seaman \& Powell, 1996). As opposed to the adaptive kernel, the fixed kernel approach is more stable for probability contours exceeding $80 \%$. Seaman et al. (1999) suggest that contours greater than $85 \%$ do not provide meaningful biological information and are less reliable. Therefore, we used only the $85 \%$ contour probabilities for all individual territory areas (see Verdolin, 2007 for details).

\section{DNA extraction and PCR amplification}

DNA was extracted from hair samples collected during trapping using Qiagen DNeasy tissue extraction kits utilizing a modified protocol for hair provided by the manufacturer. We extracted DNA two independent times following the recommended multiple tubes approach (Taberlet et al., 1996; Taberlet \& Waits, 1998). A total of 149 juveniles from 69 litters were trapped, and of those, 113 , or $75.8 \%$, were successfully genotyped from the four study plots. Six microsatellite markers were used to determine allelic diversity and heterozygosities. The markers used were CGS-08, CGS-14, CGS-12, CGS-22, CGS-25 and CGS-26 (Stevens et al., 1997; Haynie et al., 2003). Haynie et al. (2003) redesigned markers CGS-8, CGS-12, CGS-14 and CGS-22 that were originally published by Stevens et al. (1997). Markers CGS-25 and CGS-26 were used as originally published by Stevens et al. (1997). PCR amplification of the loci was performed using a 20- $\mu$ l volume that contained $5 \mu$ l extracted genomic DNA, $2 \mu$ Taq buffer, $0.8 \mu 150 \mathrm{mM}$ $\mathrm{MgCl}_{2}, 0.4 \mu 1 \mathrm{dNTP}, 0.04 \mu 1 \mathrm{Taq}$ DNA polymerase, $1.0 \mu \mathrm{l} 10 \mathrm{mM}$ fluorescent-labeled primer pair, $5 \mu \mathrm{l}$ $0.05 \mathrm{mg} / \mathrm{ml}$ BSA and $4.76 \mu \mathrm{l}$ water. Samples were submitted to the Genomic Analysis and Technology Core facility at the University of Arizona where multiplexed PCR reactions amplified with compatible labelled primers were scored with an ABI PRISM ${ }^{\circledR} 3730$ DNA Analyzer. Data were visualized using GeneScan freeware.

\section{Marker analysis}

In these populations, the numbers of alleles ranged from 3-9 per locus and were comparable to results reported by Haynie et al. (2003) for the same loci (see Verdolin \& Slobodchikoff, 2009 for details). We calculated expected and observed heterozygosities in order to test for deviations from Hardy-Weinberg, which were not significant (Verdolin \& Slobodchikoff, 2009).

When performing parentage analyses using microsatellites, genotyping errors can occur, particularly when utilizing non-invasive DNA samples (Gagneux et al., 1997). Two primary stochastic errors that may arise are allelic dropout, when an individual is scored as a homozygote due to the amplification failure of 
an allele, and false alleles, where human genotyping error, mutations, or PCR artefacts result in the true allele being misgenotyped (Taberlet et al., 1996; Gagneux et al., 1997; Taberlet \&Waits, 1998; Broquet \& Petit, 2004). Allelic dropout is more likely to have an impact on kinship inference and hence, parentage assignment (Johnson \& Haydon, 2007). However, allelic dropout can potentially be identified due to mismatches between parents and offspring, where the offspring appears homozygous for an allele detected in only one parent. Alternatively, Mendelian inconsistencies due to false alleles may be detected when an offspring is genotyped for an allele not present in either parent (Johnson \& Haydon, 2007). To reduce the incidence of these potential genotyping errors, DNA was extracted twice from each sample. While time and financial constraints precluded PCR amplification and genotyping of every sample two times as recommended for non-invasive DNA samples that typically yield low quantities of template DNA (Taberlet et al. 1996; Gagneux et al., 1997; Taberlet \& Waits, 1998; Johnson \& Haydon, 2007), a randomly chosen subset of approx. $30 \%$ of samples was independently repeated for each microsatellite to confirm assigned genotypes. If in the second amplification a different genotype was scored, the sample was repeated a third time. If the genotype could not be resolved, the locus was not included in the final analysis for that individual. Of the samples re-tested, 5.4\% (23) could not be confirmed for a given genotype.

\section{Parentage analysis}

Parentage analysis was performed using genetic exclusion, followed by submitting individuals for analysis in Cervus 3.0, which uses a maximum-likelihood approach. A log-likelihood ratio, or LOD score, was given for each candidate parent and represents the natural log of the overall likelihood ratio (Marshall et al., 1998). An LOD score of 0 implies that an individual is equally likely to as any other randomly selected individual to be a parent of the offspring, whereas a positive LOD score indicates that an individual is more likely to be a parent than a randomly selected individual. Statistical confidence was estimated for critical values at both strict (95\%) and relaxed (80\%) confidence levels based on computer simulation. Simulation parameters for both mothers and fathers were as follows: $1 \times 105$ cycles; $100 \%$ of loci typed with an error rate of 0.01 ; and the number of candidates varied for maternity or paternity analysis.

At these study sites, females and juveniles within the same territory occasionally intermingled prior to the capture of juveniles. Therefore, maternity could not always be assigned based on the burrow that a lactating female utilized. In those cases, and on the basis of behavioural observations (e.g., lactating vs. non-reproductive), only those females that were determined to be potential mothers for offspring in their respective territory were submitted for analysis, thus reducing the number of candidate mothers. In addition, only females from a juvenile's natal territory were considered potential mothers. Genetic exclusion of females was used to determine maternity or reduce the number of potential mothers, by excluding any female as a potential mother if she contained a pair of alleles, neither of which was present in the juvenile. In cases where only one female remained as a possible mother, maternity was assigned to that female. If maternity could not be resolved by genetic exclusion, the remaining potential mothers were submitted for analysis in Cervus 3.0, where the mother with the greatest LOD score was accepted as the true mother. There were ten cases of suspected homozygous-homozygous mismatching between mother and offspring and these were excluded from further analysis. There were five cases where two females were equally likely to be the mother and these offspring were also removed from further analysis.

For paternity analysis, all males sampled on the plot, both yearlings and adults, were considered as potential sires. To provide a conservative estimate of the frequency of extra-territorial paternity, only resident males were initially considered as candidate sires, unless genetic exclusion eliminated a male from consideration. A resident male that was not excluded and had a positive LOD score was assigned paternity, even if the confidence interval was below $80 \%$. If more than one resident could be assigned paternity, the one with the highest LOD score and no mismatches was accepted as the true sire. If all 
resident males were excluded as possible sires for a given offspring, based on allelic mismatches or negative LOD scores coupled with confidence intervals below $80 \%$, then all non-resident males were considered potential sires for that offspring. In this case, the non-resident male with the highest positive LOD score was accepted as the true sire of that offspring; if no non-resident male had a positive LOD score, the juvenile was not assigned a sire.

\section{Data analysis}

The frequency of multiple paternity was calculated as the proportion of all litters that were sired by more than 1 male. Separate chi-square tests were performed for each of the 19 territories, with $p$-values Bonferroni-adjusted accordingly, to test whether the frequency of paternity by residents was greater than expected given the proportion of resident males relative to all candidate males sampled. Because the relevant assumptions of analysis of variance (ANOVA) were not met, we used a Poisson regression using the generalized linear model to determine whether the number of offspring a given male sired in his territory was correlated with the number of other males present on that territory, and if among males identified as sires, age (adult or yearling), body mass at emergence from hibernation, log territory size, and standard heterozygosity were correlated with the number of offspring sired. Standard heterozygosity $\left(\mathrm{H}_{\mathrm{s}}\right)$ was measured as the proportion of heterozygous loci/mean heterozygosity of loci typed following Coltman et al. (1998).

To estimate the total number of offspring per territory, we added the number of offspring caught per territory and the highest number of unmarked juveniles observed during scanning, once trapping was complete. From this we calculated an estimated mean litter size by dividing the total number of offspring per territory by the number of females known to be potential mothers. We used general linear models (GLM) to test for a relationship between log territory size and total number offspring and mean litter size produced in a given territory. All statistical tests were performed using JMP 4.0 (SAS Institute, 2000) and Statistica. Unless otherwise stated, all tests were two-tailed and the level of significance was set to $p<0.05$.

\section{Results}

Table 1 provides a summary of group sizes, territory sizes and number of resident males for the social groups used in this study. Among females for which multiple offspring were trapped and successfully genotyped, $90.6 \%(N=32)$ had offspring sired by more than one male. Females, on average $\pm \mathrm{SD}$, mated with $2.13 \pm 0.61$ males.

Study plots varied in the percentage of the total number of candidate males that successfully sired offspring, based on paternity assignments. $\mathrm{CCl}$ had the highest percentage of males that sired offspring (75.0\%), followed by HSII (67.9\%), HSI (63.2\%) and CCII (54.6\%). Of the males that successfully sired offspring, not all males were identified as sires to multiple offspring. At CCll only $33.3 \%$ sired $\geq 2$ juveniles, while at the other plots higher values were observed $(\mathrm{CCI}=42.6 \%, \mathrm{HSII}=53.6 \%$ and $\mathrm{HSI}=$ 75.0\%).

On 2 of 19 territories, or $10.5 \%$, resident males sired more offspring on their territories than expected given the total number of candidate males (Table 2), but Fisher's combined probability test indicated that the overall trend was not significant $\left(x_{0.05[38]}^{2}=34.82, p=0.62\right)$. On $71.2 \%$ of the territories, a single nonresident male contributed equal, or higher, numbers of offspring than any individual resident male. Among the males that sired offspring, a portion of the inferred sires were yearling males, but percentages varied across the study sites. Compared to the other plots, yearling males at $\mathrm{CCl}$ sired the highest proportion of juveniles (34.3\%), followed by HSI (21.9\%), HSII (17.65\%), and at CII no juveniles were 
sired by yearling males. The Poisson regression revealed that among males identified as sires, adult males were significantly more likely to sire a greater number of offspring (Wald statistic $=3.86, N=61$, $p<0.04)$.

The number of offspring a male sired on his territory was not significantly correlated with the number of other males present on that territory (Wald statistic $=0.31, N=26, p<0.58$ ), indicating that number of other males present has little impact on a given male's reproductive success in his respective territory. Among males identified as sires, body mass at emergence from hibernation, $\mathrm{H}_{\mathrm{s}}$, and log territory size were not significantly correlated with the number of offspring sired (Body mass: Wald statistic $=0.23$, $N=45, p<0.60 ; \mathrm{H}_{\mathrm{s}}$ : Wald statistic $=0.29, N=61, p<0.59$; log territory size: Wald statistic $=0.27$, $N=53, p<0.32$ ). In addition, as log territory size increased the total number of offspring produced and mean litter size per female increased (Log territory size: $r^{2}=0.30, F_{1,17}=7.26, p<0.02$; Mean litter size: $r^{2}=0.24, F_{1,17}=5.42, p<0.03$; Figures 1 and 2).

Table 1. Summary of the territory size (ha), group size and number of resident males (adults and yearlings) in the social groups that were used for this study.

\begin{tabular}{|lcccc|}
\hline Plot & Territory no. & Territory size & Group size & $\begin{array}{c}\text { No. of } \\
\text { resident males }\end{array}$ \\
\hline $\mathrm{HSI}$ & 1 & 1586.29 & 9 & 3 \\
$\mathrm{HSI}$ & 2 & 375.18 & 3 & 2 \\
$\mathrm{HSI}$ & 3 & 1161.82 & 7 & 4 \\
$\mathrm{HSI}$ & 4 & 559.60 & 4 & 2 \\
$\mathrm{HSI}$ & 5 & 550.2 & 5 & 2 \\
$\mathrm{HSII}$ & 1 & 412.31 & 3 & 1 \\
$\mathrm{HSII}$ & 2 & 777.50 & 6 & 3 \\
$\mathrm{HSII}$ & 3 & 429.13 & 9 & 4 \\
$\mathrm{HSII}$ & 4 & 14 & 5 \\
$\mathrm{HSII}$ & 836.63 & 4 & 2 \\
$\mathrm{CCl}$ & 5 & 486.79 & 9 & 3 \\
$\mathrm{CCl}$ & 1 & 730.94 & 12 & 5 \\
$\mathrm{CCl}$ & 2 & 1765.77 & 7 & 1 \\
$\mathrm{CCl}$ & 1650.93 & 5 & 2 \\
$\mathrm{CCl}$ & 3 & 578.57 & 7 & 2 \\
$\mathrm{CCl}$ & 4 & 678.58 & 6 & 3 \\
$\mathrm{CCII}$ & 948.18 & 5 & 1 \\
$\mathrm{CCII}$ & 521.27 & 9 & 2 \\
$\mathrm{CCII}$ & 5 & 860.06 & 3 & 1 \\
\hline
\end{tabular}

Territory number corresponds to those reported in Table 2. 
Table 2. Results of the chi-square analysis testing whether resident males had a higher than expected frequency of paternity given the proportion of potential sires that were resident males relative to the number of candidate males sampled per territory.

\begin{tabular}{|lccccc|}
\hline Plot & Territory no. & $\begin{array}{c}\text { No. of } \\
\text { offspring } \\
\text { genotyped }\end{array}$ & $\begin{array}{c}\text { No. of } \\
\text { offspring sired } \\
\text { by resident } \\
\text { males }\end{array}$ & $\boldsymbol{x}^{2}$ & p-value \\
\hline $\mathrm{HSII}$ & 1 & 4 & 0 & 0.14 & 0.71 \\
$\mathrm{HSII}$ & 2 & 2 & 0 & 0.36 & 0.55 \\
$\mathrm{HSII}$ & 3 & 3 & 0 & 0.44 & 0.51 \\
$\mathrm{HSII}$ & 4 & 23 & 8 & 6.36 & 0.01 \\
$\mathrm{HSII}$ & 5 & 2 & 1 & 1.78 & 0.18 \\
$\mathrm{CCII}$ & 1 & 3 & 3 & 4.54 & 0.03 \\
$\mathrm{CCII}$ & 7 & 2 & 0.02 & 0.89 \\
$\mathrm{CCII}$ & 1 & 0 & 0.06 & 0.80 \\
$\mathrm{CCl}$ & 4 & 10 & 5 & 5.82 & 0.02 \\
$\mathrm{CCl}$ & 1 & 7 & 1 & 0.16 & 0.69 \\
$\mathrm{CCl}$ & 2 & 5 & 2 & 7.56 & $0.0006^{*}$ \\
$\mathrm{CCl}$ & 3 & 6 & 0 & 0.21 & 0.64 \\
$\mathrm{CCl}$ & 4 & 2 & 1 & 2.88 & 0.09 \\
$\mathrm{CCI}$ & 5 & 5 & 1 & 0.05 & 0.82 \\
$\mathrm{HSI}$ & 6 & 13 & 7 & 9.65 & $0.002^{*}$ \\
$\mathrm{HSI}$ & 1 & 2 & 0 & 0.24 & 0.63 \\
$\mathrm{HSI}$ & 2 & 8 & 4 & 0.49 & 0.48 \\
$\mathrm{HSI}$ & 3 & 7 & 0 & 0.82 & 0.36 \\
$\mathrm{HSI}$ & 4 & 3 & 2 & 7.69 & 0.006 \\
\hline
\end{tabular}

* Denotes significance at the Bonferroni corrected $p$-value of 0.003 .

\section{Discussion}

In this study, we successfully assigned parentage to $113 / 149$ (75.8\%) juveniles from the four study populations. Males in these populations rarely sired a significantly higher number of offspring on their respective territories (10.5\% of the time) compared to non-resident males (males occupying other territories). This value may even be an overestimate, as a resident male was assigned as sire if he had a positive LOD score for a given juvenile, even when confidence intervals were below $80 \%$ and a nonresident male had a higher LOD score for the same juvenile. Although the high degree of multiple paternity is consistent with previously published results for Gunnison's prairie dogs in this area (Travis et al., 1995, 1996), this study demonstrates that males do not gain a significant advantage securing paternity of offspring produced by females living in their territories. We also found that larger territories produced a greater number of offspring and larger mean litter sizes, suggesting potential fitness benefits for females associated with occupying a larger territory.

In female defence mating systems, males are predicted to directly control female movement patterns and sire the majority of offspring. Previous results from behavioural observations concluded that resident males in these populations never interfered with resident female movement across territory boundaries, 
and that females 'visited' other territories, ranging farther during the mating period than at any other time (Verdolin, 2007). Similarly, if males are pursuing a resource defence strategy, it is predicted that the resident male/s would contribute to a higher number of offspring in the territory than any other individual male from another territory. The results of this study present strong support that, at least the majority of the time, a resident male does not sire more offspring on his territory than any other single non-resident male.

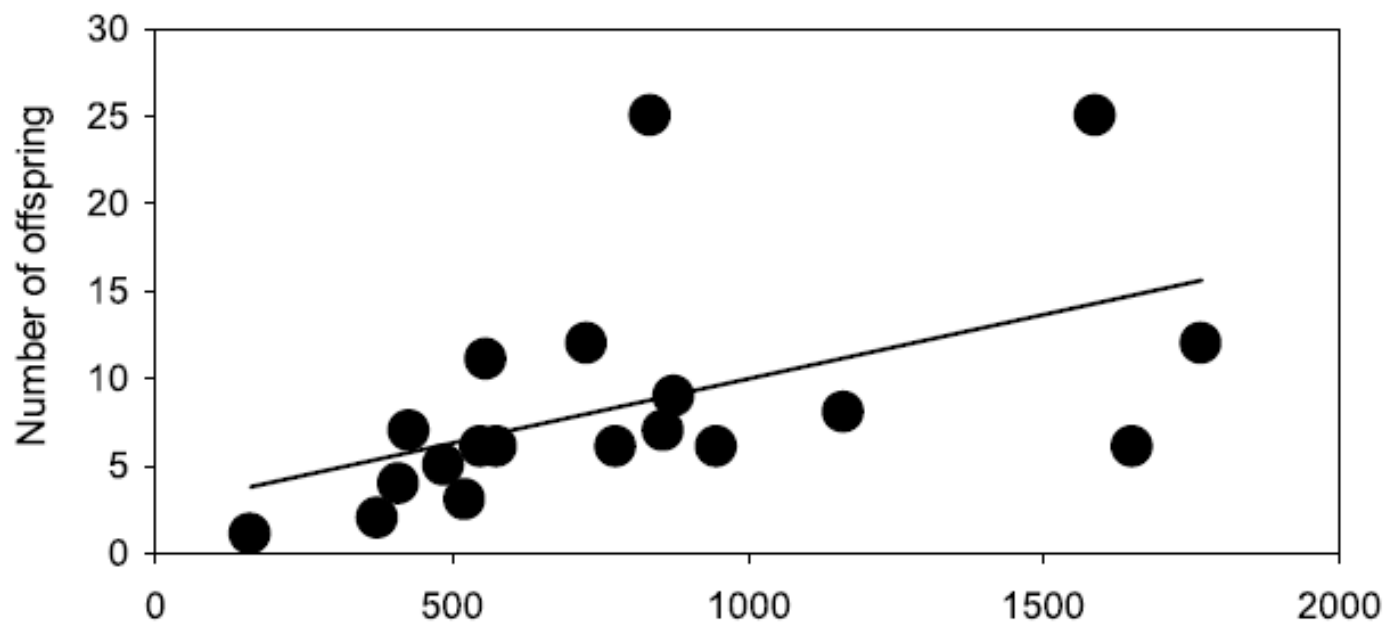

Territory Size $\mathrm{m}^{2}$

Figure 1. The relationship between territory size and the number of total offspring per territory. Linear regression ( $\log$ territory size): $\hat{y}=-31.45+6.11 x ; r^{2}=0.30, F_{1,17}=7.26, p<0.02$.

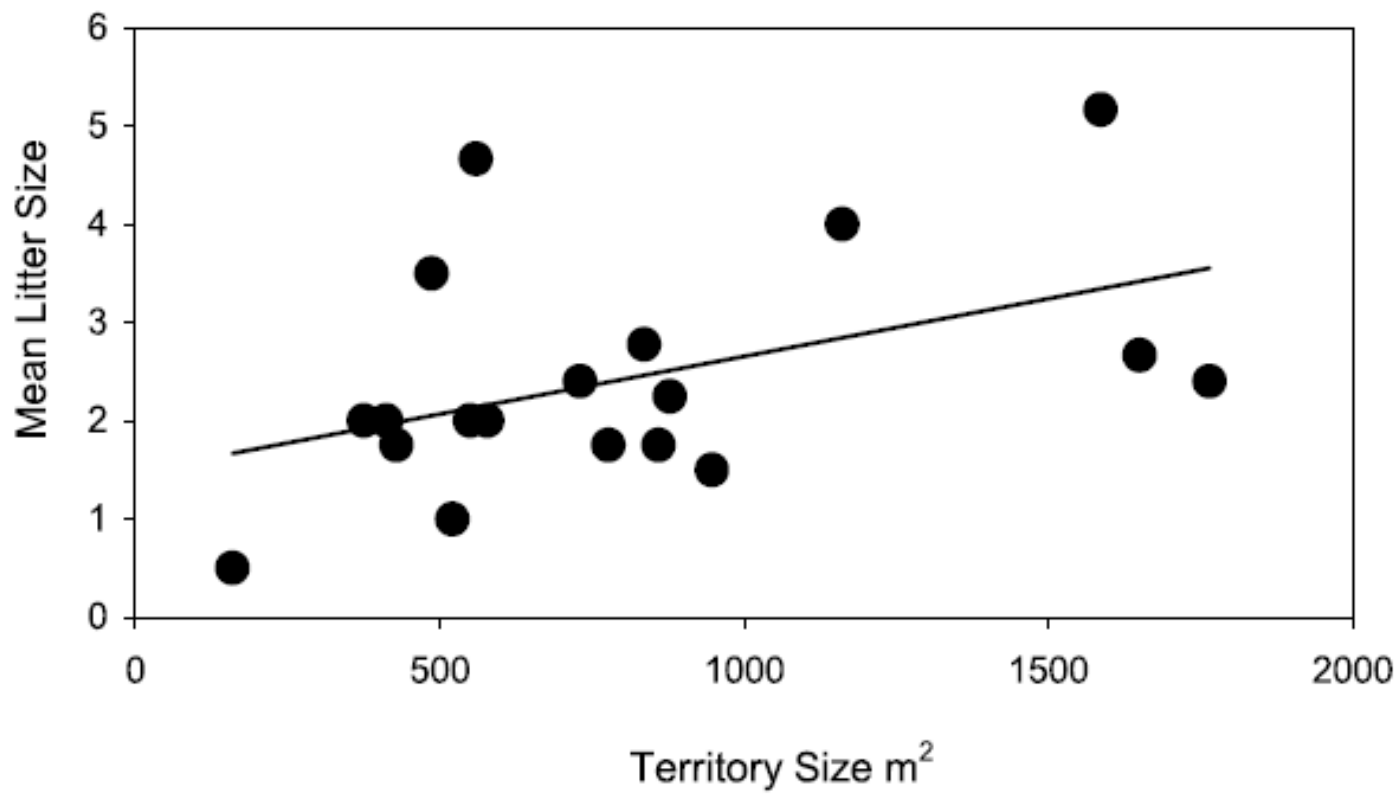

Figure 2. The relationship between territory size and mean litter size per female. Linear regression (log territory size): $\hat{y}=-4.04+0.99 x ; r^{2}=0.24, F_{1,17}=5.42, p<0.03$. 
It is possible that incomplete genotyping of all offspring biased these results by leaving a large uncertainty about the true sire and mistakenly attributing a non-resident male as the sire when the true sire was a resident. This situation is unlikely to have produced the observed relatively low siring success of resident males, for two reasons. First, we used a conservative procedure in assigning paternity to non-resident males, so that, all else being equal, any bias would actually favour assigning paternity to resident males. For instance, for the 37 juveniles assigned to resident males as sires, there were 7 cases (18.91\%) in which a non-resident male had a substantially higher LOD score (at least 1.0 units higher) for paternity in that offspring than the resident male. Second, if high variance in assigning paternity were the cause of the pattern, then there should be a link between assignment of non-resident males as sires and the number of loci successfully genotyped for a given infant. In fact, the number of loci successfully genotyped for juveniles ascribed to resident and non-resident males did not differ (Wilcoxon two-sample test: $\left.Z_{0.025[75,38]}=0.51, p<0.61\right)$.

It has been suggested that as additional males are added to a group, the ability of a single male to monopolize mating access may be compromised (Goossens et al., 1998; Reeve et al., 1998; Cohas et al., 2006). For example, extra-pair paternity in alpine marmots (Marmota marmota) increased with the number of subordinate males present (Cohas et al., 2006). Results of our study do not support this hypothesis as an explanation for multiple paternity in Gunnison's prairie dogs, or reduced monopolization of females by a single resident male, as there was no evidence that the number of males present on a territory influenced the number of offspring sired by a given resident male. In addition, there is no support for dominance hierarchies among males occupying the same territory that would create the necessary condition for such a pattern to emerge (Verdolin, 2007).

A positive correlation between male age and reproductive success has been reported in a number of species (Brooks \& Kemp, 2001; Griffith et al., 2002). Here, of the juveniles trapped and successfully assigned parentage, adult males sired significantly more offspring than yearling males. The paternity results in this study are comparable to behavioural observations reported for Gunnison's prairie dog in other populations, where approx. $24 \%$ of yearling reportedly copulated with females (Hoogland, 1999). However, since it is not possible to reliably distinguish between adults and yearlings based on body mass (Tileston \& Lechleitner, 1966), a small portion of males may have been erroneously classified as adults. In addition, we were unable to age males beyond the broad category of yearlings and adults. In the future, long-term studies of reproductive success that incorporate paternity assignment will be able to determine if, among adult males, females prefer older males.

Body size is often a good predictor of reproductive success for males, especially where sexual size dimorphism is the result of males competing for access to females (Clutton-Brock, 1989; Andersson, 1994). In Gunnison's prairie dogs there is no evidence for sexual dimorphism between males and females (Verdolin, 2007), so we examined male body mass at emergence from hibernation. We speculated that males with a higher body mass at emergence from hibernation may have occupied larger territories containing abundant resources in the previous active season or were better foragers. However, among males identified as sires, body mass at emergence from hibernation and territory size were not significant predictors of the number of offspring a male sired.

Trivers (1972) postulated that while males seek to maximize their mating opportunities, females should select males that increase the genetic fitness of their offspring, often leading to a conflict of interest among males and females. In this species, females may be attempting to enhance offspring viability by mating with multiple males, resulting in reduced individual male mating advantages. For instance, if females were closely related to resident males, one might expect a higher incidence of multiple mating as means of avoidance of genetic incompatibility due to inbreeding (Slagsvold \& Dale, 1994; Zeh \& Zeh, 1996, 1997; Jennions \& Petrie, 2000; Tregenza \& Wedell, 2000). Evidence for this has been 
demonstrated in several species including common shrews (Stockley et al., 1993), adders (Madsen \& Shine, 1992; Madsen et al., 1996, 1999) and field crickets (Tregenza \& Wedell, 2002). However, kinship results for Gunnison's prairie dogs in these study populations suggests that within territories, males and females are not more closely related than expected at random (Verdolin \& Slobodchikoff, 2009). Though increased offspring viability due to inbreeding avoidance may still explain why female Gunnison's prairie dogs mate with multiple males, it does not address why females frequently mate with males from other territories.

Alternatively, multiple mating by females due to 'genetic hedge-betting' could also dilute individual male reproductive success for some males and enhance reproductive success for other males. Recent empirical data from natural populations suggest that high levels of homozygosity reduce survival in many species (Soay sheep: Coltman et al., 1999; Song sparrows: Keller, 1998; Collared flycatcher: Kruuk et al., 2002). Thus, increasing offspring heterozygosity may improve offspring fitness (Brown, 1997; Foerster et al., 2003). Here we found that, among males identified as sires, standard heterozygosity was not a significant predictor of the number of offspring sired. However, high genetic diversity at microsatellites may not accurately reflect overall genomic heterozygosity, or patterns of variability present in loci that are targets of natural selection (O'Brien, 1994; Hedrick, 1999). Because microsatellites occur in the noncoding region of the genome and may not be correlated with fitness, males with greater heterozygosity at microsatellite loci may not represent males with the highest genetic variability at loci strongly associated with adaptive differences. Indeed, individual heterozygosity measured by molecular markers is weakly correlated with heterozygosity across the genome, particularly with fewer than 20 loci, and estimating $\mathrm{H}$ using only a few markers can be problematic (DeWoody \& DeWoody, 2005; Masters et al., 2009).

Given that multiple mating is frequent in all populations of Gunnison's prairie dogs studied to date (this study; Travis et al., 1995, 1996; Haynie et al., 2003), why are males territorial? One possibility may be that although males are attempting to maximize direct reproductive advantages by mating with females within their territory, conflicting female mating strategies result in few, if any, resident males gaining a reproductive advantage with females on their territories. For example, Hoogland (1998) suggests that multiple mating by female Gunnison's prairie dogs increases the probability of insemination, although he found that the probability of parturition did not differ between females that copulated with one versus two males. Because copulation almost always occurs below ground, we were unable to test this hypothesis by accurately assessing how many males a female mated with. Hoogland (1998) also reports that litter size for a given female increased with the number of males she mated with. In this study, not all offspring were successfully trapped, and though estimates of mean litter size per territory were possible by combining trapped offspring with counts of the number of unmarked offspring remaining in a given territory, we were unable to confidently determine individual litter size for all females.

In this study, we found that the paternity results strongly suggest that males are not benefiting from a female defence or resource defence polygyny strategy. Resident males do not appear to have a consistent reproductive advantage with females that they co-defend territories with year-round. Furthermore, the behavioural strategies of males do not conform to predictions that emerge from either model (e.g., control of female movement, same-sex defence, sexual dimorphism; see Verdolin, 2007 for further details).We suggest that female mating strategies are influencing individual male reproductive success in these populations. Previous data from these study populations showed a clear positive relationship between territory size, group size and food abundance and larger territories have a higher per-capita amount of food available (Verdolin, 2007, 2009). Territoriality by both males and females, coupled with year-round cooperative defence, may facilitate enhanced access to food resources critical to overwinter survival (Verdolin, 2009). Therefore, males, like females, may be territorial in order to secure sufficient resources, while individual mating strategies are secondary to the social structure that emerges 
in response to resource availability. Whether females are choosing mates based on some superior phenotype we did not measure or mating with males based on genetic compatibility at more functional loci (e.g., major histocompatibility complex), remains to be explored and may ultimately elucidate what factors influence the high prevalence of multiple paternity and explain patterns of male reproductive success in this species.

We also found that larger territories produced a higher number of offspring, which might be expected since larger territories generally had more females. More importantly, mean litter size per female was larger on larger territories and may explain the potential fitness benefits for females to settle on particular territories. Although not all juveniles were accounted for, it is unlikely that there is any systematic bias that would skew trapping success in favour of larger territories. So it appears that there is some differential advantage conferred to females depending on which territory they occupy.

We caution any over-interpretation of these results as we only have mean litter size and cannot account for the variance in reproductive success among individual females within territories.

Our results have important implications for studies that do not distinguish between social and mating systems, because they suggest conclusions about mating systems may be confounded by different selective pressures acting on the social systems. Some fitness benefits might accrue through a social system (e.g., for prairie dogs, access to food resources, burrows, and hibernacula), while other fitness benefits might accrue through genetic factors (e.g., inbreeding-avoidance, maximizing genetic heterozygosity). These different fitness components can lead to divergent social and mating systems within a species, but when summed together maximize the probability of survival and reproductive success of both sexes. Consequently, future studies should evaluate and discuss the selective pressures shaping social and mating systems independently.

\section{Acknowledgements}

We are grateful to Dr. Charles Janson, for his guidance and invaluable contribution to this manuscript. We would also like to thank Drs Kenneth Armitage, John True, Patricia Wright, and two anonymous reviewers, whose comments and suggestions greatly improved this manuscript. For unbelievable field support, veterinary services, and friendship, a heartfelt thanks to Dr. David Washabau. This project could not have been completed without many people dedicating their time and effort in the field, including Bill and Theresa Emig, Carolyn Parker, Perry Crompton, Kristen Hoss, Jessica Hagan and many others. For help in the lab we would like to thank undergraduates Ariba Hashmi and Sana Hashmi. This study was supported by grants from the American Museum of Natural History, Sigma Xi and the American Society of Mammalogists. Generous donations of microchips were made by Schlering-Plough and sunflower seeds were kindly provided by Western Organics, Inc. For charitably allowing use of tomahawk traps we thank Norris Dodd. Vegetation data were analyzed in the FERTL Lab housed in the Department of Ecology and Evolution, Stony Brook University. Lastly, we thank the City of Flagstaff, Arizona Game and Fish Department and the Arizona State Land Trust Department for all necessary permits. This project was approved by Stony Brook University Animal Care and Use Committee (Permit no. 1290). 


\section{References}

Amos, W., Wilmer, J.W., Fullard, K., Burg, T.M., Croxall, J.P., Bloch, D. \& Coulson, T. (2001). The influence of parental relatedness on reproductive success. - Proc. Roy. Soc. Lond. B: Biol. 268 : 2021-2027.

Andersson, M. (1994). Sexual selection. —Princeton University Press, Princeton, NJ.

Birkhead, T.R., Atkin, L. \&Moller, A.P. (1987). Copulation behaviour of birds.-Behaviour 101: 101-138.

Boellstorff, D.E., Owings, D.H., Penedo, M.C.T. \& Hersek, M.J. (1994). Reproductive behavior and multiple paternity of California ground-squirrels. - Anim. Behav. 47: 1057-1064.

Bradbury, J.W. \& Vehrencamp, S.L. (1977). Social organization and foraging in emballonurid bats, 3 : mating systems. - Behav. Ecol. Sociobiol. 2: 1-17.

Brooks, R. \& Kemp, D.J. (2001). Can older males deliver the good genes? - Trends Ecol. Evol. 16: 308313.

Broquet, T. \& Petit, E. (2004). Quantifying genotyping errors in noninvasive population genetics. - Mol. Ecol. 13: 3601-3608.

Brown, J.L. (1997). A theory of mate choice based on heterozygosity. - Behav. Ecol. 8 60-65.

Clutton-Brock, T.H. (1989). Mammalian mating systems. - Proc. Roy. Soc. Lond. B: Biol. 236: 339-372.

Clutton-Brock, T.H., Albon, S.D. \& Guinness, F.E. (1988). Reproductive success in male and female red deer. - In: Reproductive success (Clutton-Brock, T.H., ed.). University of Chicago Press, Chicago, IL, p. 325-343.

Cohas, A., Yoccoz, N.G., Da Silva, A., Goossens, B. \& Allaine, D. (2006). Extra-pair paternity in the monogamous alpine marmot (Marmota marmota): the roles of social setting and female mate choice. - Behav. Ecol. Sociobiol. 59: 597-605.

Coltman, D.W., Bowen,W.D. \&Wright, J.M. (1998). Birth rates and neonatal survival of harbor seal pups are positively correlated with genetic variation measured by microsatellites. - Proc. Roy. Soc. Lond. B: Biol. 265: 803-809.

Coltman, D.W., Pilkington, J.G., Smith, J.A. \& Pemberton, J.M. (1999). Parasite-mediated selection against inbred Soay sheep in a free-living island population.-Evolution. 53: 1259-1267.

Davies, N.B. (1991). Mating systems. — In: Behavioural ecology: an evolutionary approach (Krebs, J.R. \& Davies, N.B., eds). Blackwell Scientific, Oxford, p. 263-299.

DeWoody, Y.D. \& DeWoody, J.A. (2005). On the estimation of genome-wide heterozygosity using molecular markers.-J. Hered. 96: 85-88.

Emlen, S. \& Oring, L.W. (1977). Ecology, sexual selection, and evolution of mating systems. - Science 197: 215-223.

ESRI (2000). Arcview, Version 3.2a.-ESRI, Redlands, CA.

Fitzgerald, J.P. \& Lechleitner, R.R. (1974). Observation on the biology of Gunnison's prairie dog in central Colorado. - Am. Midl. Nat. 92: 146-163.

Foerster, K., Delhey, K., Johnsen, A., Lifjeld, J.T.\&Kempenaers, B. (2003). Females increase offspring heterozygosity and fitness through extra-pair matings. — Nature 425: 714-717.

Gagneux, P., Boesch, C. \& Woodruff, D.S. (1997). Microsatellite scoring errors associated with noninvasive genotyping based on nuclear DNA amplified from shed hair. - Mol. Ecol. 6: 861868.

Goossens, B., Graziani, L., Waits, L.P., Farand, E., Magnolon, S., Coulon, J., Bel, M.C., Taberlet, P. \& Allaine, D. (1998). Extra-pair paternity in the monogamous Alpine marmot revealed by nuclear DNA microsatellite analysis. - Behav. Ecol. Siociobiol. 43: 281-288.

Griffith, S.C., Owens, I.P.F. \& Thuman, K.A. (2002). Extra pair paternity in birds: a review of interspecific variation and adaptive function. - Mol. Ecol. 11: 2195-2212.

Hanken, J. \& Sherman, P.W. (1981).Multiple paternity in Beldings ground-squirrel litters.- Science 212: 351-353. 
Haynie, M.L., Vandenbussche, R.A., Hoogland, J.L. \& Gilbert, D.A. (2003). Parentage, multiple paternity, and breeding success in Gunnison's and Utah prairie dogs. - J. Mammal. 84: 1244-1253.

Hedrick, P.W. (1999). Perspective: highly variable loci and their interpretation in evolution and conservation. - Evolution 53: 313-318.

Höglund, J., Piertney, S.B., Alatalo, R.V., Lindell, J., Lundberg, A. \& Rintiaki, P.T. (2002). Inbreeding depression and male fitness in Black Grouse. — Proc. Roy. Soc. Lond. B: Biol. 269: 711-715.

Hoogland, J.L. (1998). Why do female Gunnison's prairie dogs copulate with more than one male? Anim. Behav. 55: 351-359.

Hoogland, J.L. (1999). Philopatry, dispersal, and social organization of Gunnison's prairie dogs.-J. Mammal. 80: 243-251.

Jennions, M.D. \& Petrie, M. (2000). Why do females mate multiply? A review of the genetic benefits.Biol. Rev. 75: 21-64.

Johnson, P.C.D. \& Haydon, D.T. (2007). Maximum-likelihood estimation of allelic dropout and false allele error rates from microsatellite genotypes in the absence of reference data.- Genetics 175: 827842.

Keller, L.F. (1998). Inbreeding and its fitness effects in an insular population of song sparrows (Melospiza melodia). -Evolution 52: 240-250.

King, J.A. (1955). Social behaviour, social organization, and population dynamics in a black-tailed prairiedog town in the Black Hills of South Dakota. — University of Michigan, Ann Arbor, MI.

Kitchen, A.M., Gese, E.M., Waits, L.P., Karki, S.M. \& Schauster, E.R. (2006). Multiple breeding strategies in the swift fox, Vulpes velox. - Anim. Behav. 71: 1029-1038.

Kodric-Brown, A. \& Brown, J.H. (1984). Truth in advertising: the kinds of traits favored by sexual selection. - Am. Nat. 124: 309-323.

Kruuk, L.E.B., Sheldon, B.C. \& Merilä, J. (2002). Severe inbreeding depression in collared flycatchers (Ficedula albicollis). — Proc. Roy. Soc. Lond. B: Biol. 269: 1581-1589.

Kyle, C.J., Karels, T.J., Davis, C.S., Mebs, S., Clark, B., Strobeck, C. \& Hik, D.S. (2007). Social structure and facultative mating systems of hoary marmots (Marmota caligata). —Mol. Ecol. 16: 12451255.

Lacey, E.A., Wieczorek, J.R. \& Tucker, P.K. (1997). Male mating behaviour and patterns of sperm precedence in Arctic ground squirrels. - Anim. Behav. 53: 767-779.

Lane, J.E., Boutin, S., Gunn, M.R., Slate, J. \& Coltman, D.W. (2007). Genetic relatedness of mates does not predict patterns of parentage in North American red squirrels._Anim. Behav. 74: 611-619.

Lott, D.F. (1991). Intraspecific variation in the social systems of wild vertebrates. - Cambridge University Press, Cambridge.

Madsen, T. \& Shine, R. (1992). A rapid, sexually selected shift in mean body size in a population of snakes.-Evolution 46: 220-1224.

Madsen, T., Shine, R., Olsson, M. \&Wittzell, H. (1999). Conservation biology-restoration of an inbred adder population. - Nature 402: 34-35.

Madsen, T., Stille, B. \& Shine, R. (1996). Inbreeding depression in an isolated population of adders Vipera berus.- Biol. Conserv. 75: 113-118.

Mainguy, J., Cöté, S.D., Festa-Bianchet, M. \& Coltman, D. (2009). Father-offspring phenotypic correlations suggest intralocus sexual conflict for a fitness-linked trait in a wild sexually dimorphic mammal.-Proc. Roy. Soc. Lond. B: Biol. 276: 4067-4075.

Manning, J.T. (1985). Choosy females and correlates of male age. - J. Theor. Biol. 116: 349-354.

Marshall, T.C., Slate, J., Kruuk, L.E.B. \& Pemberton, J.M. (1998). Statistical confidence for likelihoodbased paternity inference in natural populations. - Mol. Ecol. 7: 639-655.

Masters, B.S., Johnson, L.S., Johnson, B.G.P., Neely, C.J. \& Williams, K.L. (2009). "Compatible alleles" and extra-par paternity: conclusions depend on the microsatellite loci used.—Condor 111: 365369. 
Mays, H.L. \& Hill, G.E. (2004). Choosing mates: good genes versus genes that are a good fit.- Trends Ecol. Evol. 19: 554-559.

McElligott, A.G., Gammell, M.P., Harty, H.C., Paini, D.R., Murphy, D.T., Walsh, J.T. \& Hayden, T.J. (2001). Sexual size dimorphism in fallow deer (Dama dama): do larger, heavier males gain greater mating success? —Behav. Ecol. Sociobiol. 49: 266-272.

Michener, G.R. \& McLean, I.G. (1996). Reproductive behaviour and operational sex ratio in Richardson's ground squirrels. -Anim. Behav. 52: 743-758.

Moore, J.A., Daugherty, C.H. \& Nelson, N.J. (2009). Larger male advantage: phenotypic and genetic correlates of territoriality in tuatara. - J. Herpetol. 43: 570-578.

Murie, J.O. (1995). Mating behaviour of Columbian ground squirrels. I. Multiple mating by females and multiple paternity. - Can. J. Zool. 73: 1819-1826.

Neff, B.D. \& Pitcher, T.E. (2005). Genetic quality and sexual selection: an integrated framework for good genes and compatible genes.- Mol. Ecol. 14: 19-38.

O'Brien, S.J. (1994). Genetic and phylogenetic analyses of endangered species. - Annu. Rev. Genet. 28: 467-489.

Orians, G. (1969). On evolution of mating systems in birds and mammals. — Am. Nat. 103: 589-602.

Rayor, L.S. (1988). Social organization and space-use in Gunnison's prairie dog. - Behav. Ecol. Sociobiol. 22: 69-78.

Reeve, H.K., Emlen, S.T. \& Keller, L. (1998). Reproductive sharing in animal societies: reproductive incentives or incomplete control by dominant breeders?-Behav. Ecol. 9: 267-278.

SAS Institute (2000). Statistics and graphics guide, Version 4.- SAS Institute, Cary, NC.

Schwagmeyer, P.L. \& Foltz, D.W. (1990). Factors affecting the outcome of sperm competition in 13-lined ground-squirrels. - Anim. Behav. 39: 156-162.

Seaman, D.E., Millspaugh, J.J., Kernohan, B.J., Brundidge, G.C., Raedke, K.J. \& Gitzen, R.A. (1999). Effects of sample size on kernel home range estimators. — J. Wildlife Manage. 63: 739-747.

Seaman, D.E. \& Powell, R.A. (1996). An evaluation of the accuracy of kernel density estimators for home range analysis. -Ecology 77: 2075-2085.

Sherman, P.W. (1989). Mate guarding as paternity insurance in Idaho ground-squirrels. - Nature 338: 418-420.

Shine, R., Olsson, M., Moore, I.T., Lemaster, M.P., Greene, M. \& Mason, R.T. (2000). Body size enhances mating success in Garter Snakes. —Anim. Behav. 59: F4-F11.

Slagsvold, T. \& Dale, S. (1994). Why do female pied flycatchers mate with already mated males deception or restricted mate sampling. - Behav. Ecol. Sociobiol. 34: 239-250.

Slobodchikoff, C.N. (1984). Resources and the evolution of social behaviour. — In: A new ecology (Price, P.W., Slobodchikoff, C.N. \& Gaud,W.S., eds).Wiley Interscience, New York, NY, p. 227-251.

Stevens, S., Coffin, J. \& Strobeck, C. (1997). Microsatellite loci in Columbian ground squirrels Spermophilus columbianus. -Mol. Ecol. 6: 493-495.

Stockley, P., Searle, J.B., Macdonald, D.W. \& Jones, C.S. (1993). Female multiple mating behaviour in the common shrew as a strategy to reduce inbreeding. - Proc. Roy. Soc. Lond. B: Biol. 254: 173-179.

Taberlet, P., Griffin, S., Goossens, B., Questiau, S., Manceau, V., Escaravage, N., Waits, L.P. \& Bouvet, J. (1996). Reliable genotyping of samples with very low DNA quantities using PCR.- Nucleic Acids Res. 24: 3189-3194.

Taberlet, P. \& Waits, L.P. (1998). Non-invasive genetic sampling. - Trends Ecol. Evol. 13: 26-27.

Thuman, K.A. \& Griffith, S.C. (2005). Genetyic similarity and the nonrandom distribution of paternity in a genetically highly polyandrous shorebird. —Anim. Behav. 69: 765-770.

Tileston, J.V. \& Lechleitner, R.R. (1966). Some comparisons of black-tailed and white-tailed prairie dogs in north-central Colorado. - Am. Midl. Nat. 75: 292-316. 
Travis, S. \& Slobodchikoff, C.N. (1993). Effects of food resources on the social system of Gunnison's prairie dogs.—Can. J. Zool. 71: 1186-1192.

Travis, S.E., Slobodchikoff, C.N. \& Keim, P. (1995). Ecological and demographic effects on intraspecific variation in the social system of prairie dogs.- Ecology 76: 1794-1803.

Travis, S.E., Slobodchikoff, C.N. \& Keim, P. (1996). Social assemblages and mating relationships in prairie dogs: a DNA fingerprint analysis. - Behav. Ecol. 7: 95-100.

Tregenza, T. \& Wedell, N. (2000). Genetic compatibility, mate choice and patterns of parentage: invited review.-Mol. Ecol. 9: 1013-1027.

Tregenza, T. \& Wedell, N. (2002). Polyandrous females avoid costs of inbreeding.-Nature 415: 71-73.

Trivers, R.L. (1972). Parental investment and sexual selection.--In: Sexual selection and the descent of man (Campbell, B., ed.). Aldine, Chicago, IL, p. 136-179.

Vanpé, C., Kjellander, P., Gaillard, J.M., Cosson, J.F., Galan, M. \& Hewison, A.J.M. (2009). Multiple paternity occurs with low frequency in the territorial roe deer, Capreolus capreolus.-Biol. J. Linn. Soc. 97: 128-139.

Vehrencamp, S.L. \& Bradbury, J.W. (1984). Mating systems and ecology.-In: Behavioural ecology: an evolutionary approach (Krebs, J.R. \& Davies, N.B., eds). Blackwell Scientific, Oxford, p. 251-278.

Verdolin, J.L. (2007). Resources, not male mating strategies, determine social structure in Gunnison's prairie dogs.- Behaviour 144: 1361-1382.

Verdolin, J.L. (2009). Gunnison's prairie dog (Cynomys gunnisoni): testing the resource dispersion hypothesis. - Behav. Ecol. Sociobiol. 63: 789-799.

Verdolin, J.L. \& Slobodchikoff, C.N. (2009). Resources, not kinship, determine social patterning in the territorial Gunnison's prairie dog (Cynomys gunnisoni).-Ethology 115: 59-69.

Verner, J. (1964). Evolution of polygamy in long-billed marsh wren. — Evolution 18: 252-261.

Verner, J. \&Willson, M.F. (1966). Influence of habitats on mating systems of North American passerine birds.- Ecology 47: 143-147.

Wittenberger, J. (1976). The ecological factors selecting for polygyny in altricial birds. - Am. Nat. 10: 779-799.

Worton, B. (1995). Using Monte Carlo simulations to evaluate kernel-based home range estimators.- J. Wildlife Manage. 59: 794-800.

Zeh, J.A. \& Zeh, D.W. (1996). The evolution of polyandry I: intragenomic conflict and genetic incompatibility. - Proc. Roy. Soc. Lond. B: Biol. 263: 1711-1717.

Zeh, J.A. \& Zeh, D.W. (1997). Homozygosity, self-recognition, and aggressive ability in the sea anemone, Anthopleura elegantissima. - Am. Nat. 149: 785-789. 